\title{
Expression Analysis of Aquaporins from Desert Truffle Mycorrhizal Symbiosis Reveals a Fine-Tuned Regulation Under Drought
}

\author{
Alfonso Navarro-Ródenas, ${ }^{1}$ Gloria Bárzana, ${ }^{2}$ Emilio Nicolás, ${ }^{3}$ Andrea Carra, ${ }^{4}$ Andrea Schubert, ${ }^{5}$ and \\ Asunción Morte ${ }^{1}$ \\ ${ }^{1}$ Departamento Biología Vegetal (Botánica), Facultad de Biología, Universidad de Murcia, Campus de Espinardo, 30100 \\ Murcia, Spain; ${ }^{2}$ Departamento de Microbiología del Suelo y Sistemas Simbióticos, Estación Experimental del Zaidín \\ (CSIC), Profesor Albareda, no. 1, Granada 18008, Spain; ${ }^{3}$ Departamento de Riego, Centro de Edafología y Biología \\ Aplicada del Segura (CEBAS-CSIC), 30100 Murcia, Spain; ${ }^{4}$ stituto di Virologia Vegetale, CNR, Strada delle Cacce 73, \\ 10135 Turin, Italy; ${ }^{5}$ Department of Agricultural, Forest and Food Sciences, University of Turin, Via Leonardo da Vinci 44, \\ Grugliasco, 10095 Turin, Italy
}

Submitted 17 July 2012. Accepted 26 April 2013.

We have performed the isolation, functional characterization, and expression analysis of aquaporins in roots and leaves of Helianthemum almeriense, in order to evaluate their roles in tolerance to water deficit. Five cDNAs, named HaPIP1; 1, HaPIP1;2, HaPIP2;1, HaPIP2;2, and HaTIP1;1, were isolated from $H$. almeriense. A phylogenetic analysis of deduced proteins confirmed that they belong to the water channel proteins family. The HaPIP1;1, HaPIP2;1, and HaTIP1;1 genes encode functional water channel proteins, as indicated by expression assays in Saccharomyces cerevisiae, showing divergent roles in the transport of water, $\mathrm{CO}_{2}$, and $\mathrm{NH}_{3}$. The expression patterns of the genes isolated from $\boldsymbol{H}$. almeriense and of a previously described gene from Terfezia claveryi (TcAQP1) were analyzed in mycorrhizal and nonmycorrhizal plants cultivated under wellwatered or drought-stress conditions. Some of the studied aquaporins were subjected to fine-tuned expression only under drought-stress conditions. A beneficial effect on plant physiological parameters was observed in mycorrhizal plants with respect to nonmycorrhizal ones. Moreover, stress induced a change in the mycorrhizal type formed, which was more intracellular under drought stress. The combination of a high intracellular colonization, together with the fine-tuned expression of aquaporins could result in a morphophysiological adaptation of this symbiosis to drought conditions.

Terfezia claveryi Chatin is a desert truffle that establishes ectendomycorrhizal symbiosis with species of the genus Helianthemum (Morte et al. 2008). T. claveryi has become an alter-

Corresponding author: A. Morte; Telephone: +34 868887146; Fax: +34 868883963; E-mail: amorte@um.es

Nucleotide sequence data is available in the GenBank database under the following accession numbers: HaTIP1;1 (HQ234609), HaPIP1;1 (JF491349), HaPIP1;2 (JF491350), HaPIP2;1 (JF491351), HaPIP2;2 (JF491352),

* The $e$-Xtra logo stands for "electronic extra" and indicates that one supplementary table is published online and Figure 2 appears in color online.

(C) 2013 The American Phytopathological Society native agricultural crop in semiarid areas because of the low water input required for its cultivation (Morte et al. 2009). Although the association is well adapted to semiarid climates (Morte et al. 2000, 2010; Navarro-Ródenas et al. 2011), the fungus requires localized outbreaks of rain to develop and fructify (Honrubia et al. 2007; Navarro-Ródenas et al. 2011). In a recent 10-year cultivation trial, carpophores fructified yearly and production increased in time because of suitable land management techniques and irrigation (Morte et al. 2008, 2009). In contrast, in conditions of overwatering, plants do not lose their leaves in summer and truffle harvesting does not occur (Morte et al. 2010). These phenomena do not occur in natural populations or in plantations under dry conditions, which receive only deficit irrigation. Thus, proper irrigation scheduling is one of the most important factors for maintaining successful cultivation (Morte et al. 2008). To this aim, it is necessary to know which mechanisms are involved in tolerance to drought in the mycorrhizal (M) symbiosis Helianthemum almeriensel T. claveryi, and how water supply might affect these mechanisms.

Although water stress favors growth and fructification of the desert truffle, the symbiotic association also mitigates the negative effects of drought stress on the plant partner. Morte and associates (2000) showed that, under nursery conditions, this mitigation could be attributed to higher chlorophyll content and nutritional status in $\mathrm{M}$ than in nonmycorrhizal (NM) $H$. almeriense plants. The same authors also observed an increase of plant hydraulic conductance in $\mathrm{M}$ plants, which was more evident under drought-stress conditions. Similar results have been recently observed in the $H$. sessiliflorum/T. boudieri mycorrhiza, where the enhanced ability of $\mathrm{M}$ plants to survive in the harsh desert conditions was attributed to their higher $\mathrm{CO}_{2}$ assimilation rates and water use efficiency which, in turn, are controlled by modification of hydraulic conductances (Turgeman et al. 2011).

In roots, the radial transport of water is a combination of three pathways (apoplastic, symplastic, and transcellular). The relative contribution of these pathways is modulated by environmental factors such as drought stress (Steudle 2000). However, water has to pass, at least at certain points (exo- and endodermal barriers), the plasma membrane before entering the vascular system (Sánchez-Díaz and Aguirreolea 2008b). In this sense, the discovery of aquaporins (AQP) in plants caused a 
significant change in the understanding of plant water relations. AQP are water-channel proteins that facilitate and regulate the passive movement of water and other small polar molecules (Zardoya 2005). Plant AQP are subdivided into five groups based on their amino acid sequence homology: plasma membrane intrinsic proteins (PIP), tonoplast intrinsic proteins (TIP), nodulin-like intrinsic proteins, small and basic intrinsic proteins, and unrecognized intrinsic proteins (XIP), the group most recently described (Danielson and Johanson 2008; Park et al. 2010; Sade et al. 2009).

Several studies have focused on the role of mycorrhizae in protection against drought stress, demonstrating that symbiosis often results in altered rates of water movement into, through, and out of the host plants, with consequences for tissue hydration and plant physiology (Augé 2001; Marjanović et al. 2005a,b; Morte et al. 2000; Ruiz-Lozano 2003). In some cases, the effects of $\mathrm{M}$ symbiosis on plant water relations have been attributed to alteration of plant AQP gene expression (Aroca et al. 2007; Ouziad et al. 2006; Porcel et al. 2006; Ruiz-Lozano and Aroca 2008; Ruiz-Lozano et al. 2006). Furthermore, upregulation of plant AQP that could be involved in water, glycerol, and ammonia exchange processes between symbionts has been described in arbuscular mycorrhiza (Giovannetti et al. 2012; Uehlein et al. 2007). However, although it is well known that $\mathrm{M}$ mycelium transports water from the soil to the roots (Duddridge et al. 1980; Marulanda et al. 2003; Ruiz-Lozano and Azcón 1995), only three reports have targeted AQP of M fungi and their functions (Aroca et al. 2009; Dietz et al. 2011; Navarro-Ródenas et al. 2012b). Considering the $H$. almeriense/T. claveryi symbiosis, an AQP gene from the fungus (TcAQP1) has been previously identified and characterized as being able to increase water and $\mathrm{CO}_{2}$ conductivity and to promote drought tolerance of the mycelium grown in vitro (Navarro-Ródenas et al. 2012b), whereas no AQP of the plant partner have been described up to now.

Fig. 1. Phylogenetic comparison of the five different major intrinsic proteins (MIP) from Helianthemum almeriense (Ha) pointed and the complete set of 35 and 33 MIP from Arabidopsis thaliana (At) and Zea mays (Zm), respectively, and two unrecognized intrinsic proteins (XIP) from Gossypium hirsutum (Gh) and Solanum lycopersicum (Sl). Deduced amino acid sequences were aligned using Mega 4 and the phylogenetic tree was generated using the neighbor-joining tree $(1,000$ resampling $)$ method. NIP = nodulin-like intrinsic protein, PIP = plasma membrane intrinsic protein, SIP $=$ small and basic intrinsic protein, and TIP $=$ tonoplast intrinsic protein. AtNIP1;1 (NP_567572.1), AtNIP1;2 (NP_193626.1), AtNIP2;1 (Q8W037.2), AtNIP3;1 (Q9C6T0.2), AtNIP4;1 (NP_198597.1), AtNIP4;2 (NP_198598.1), AtNIP5;1 (NP_192776.1), AtNIP6;1 (NP_178191.1), AtNIP7;1 (NP_566271.1), AtPIP1;1 (NP_001078323.1), AtPIP1;2 (NP_ 001078066.1), AtPIP1;3 (NP_171668.1), AtPIP1;4 (NP_567178.1), AtPIP1;5 (NP_194071.1), AtPIP2;1 (NP_190910.1), AtPIP2;2 (NP 181254.1), AtPIP2;3 (NP_181255.1), AtPIP2;4 (NP_200874.1), AtPIP2;5 (NP_191042.1), AtPIP2;6 (NP_181434.1), AtPIP2;7 (NP_195236.1); AtPIP2;8 (NP_179277.1), AtSIP1;1 (NP_187059.1), AtSIP1;2 (NP_ 197330.1), AtSIP2;1 (NP_191254.1), AtTIP1;1(NP_181221.1), AtTIP1; (NP_189283.1), AtTIP1;3 (NP_192056.1), AtTIP2;1 (NP_188245.1), AtTIP2;2 (NP 193465.1), AtTIP2;3 (NP 199556.1); AtTIP3;1 (NP 177462.1), AtTIP3;2 (NP_173223.1), AtTIP4;1 (NP_180152.1), AtTIP5; 1 (NP_190328.1), GhXIP1;1 (ADE34299.1), SIXIP (BT014197.1), ZmNIP1;1 (AAK26750.1), ZmNIP2;1 (AAK26751.1), ZmNIP2;2 (AAK26752.1), ZmNIP3;1 (AAK26753.1), ZmPIP1;1 (CAA57955.1), ZmPIP1;2 (AAD29676.1), ZmPIP1;3 (AAK26754.1), ZmPIP1;4 (AAK26755.1), ZmPIP1;5 (AAK26756.1), ZmPIP1;6 (AAK26757.1), ZmPIP2;1 (AAK26758.1), ZmPIP2;2 (AAK26759.1), ZmPIP2;3 (AAK26760.1), ZmPIP2;4 (AAK26761.1), ZmPIP2;5 (AAD28761.1), ZmPIP2;6 (AAK26762.1), ZmPIP2;7 (AAK26763.1), ZmSIP1;1 (AAK26764.1), ZmSIP1;2 (AAK26765.1), ZmSIP2;1 (AAK26766.1), ZmTIP1;1 (AAC09245.1), ZmTIP1;2 (AAK26767.1), ZmTIP2;1 (AAK26768.1), ZmTIP2;2 (AAK26769.1), ZmTIP2;3 (AAK26770.1).
Thus, the main objective of the present study was to identify and functionally characterize $H$. almeriense AQP and to analyze the expression of these genes and of the fungal AQP TcAQP1 in M plants, under different water supply conditions, with the aim of understanding whether they are involved in adaptation to drought of the two symbionts.

\section{RESULTS}

\section{Cloning of $\mathrm{H}$. almeriense AQP.}

Three different cDNA bands of approximately 450, 600, and $350 \mathrm{bp}$ were isolated with TIP-sense/antisense (S/AS), PIPS/AS, and PIP-forward/reverse (for/rev) degenerated primers, respectively. Sequencing revealed that the encoded amino acid sequences displayed high $(>80 \%)$ identity with those of plant AQP. Five sequences were cloned; based on homology analysis, two different 600-bp clones showed high similarity to PIP1 genes while two 350-bp clones presented high similarity to PIP2 genes. The 450-bp clone showed homology with the TIP group.

Phylogenetic analysis confirmed that four of the isolated sequences are plasma membrane proteins: HaPIP1;1 and HaPIP1;2 cluster with the PIP1 subfamily while HaPIP2;1 and HaPIP2;2 cluster with the PIP2 subfamily. The other protein (HaTIP1;1) belongs to the TIP1 group of the TIP subfamily (Fig. 1). Thus, a proposed nomenclature for $H$. almeriense major

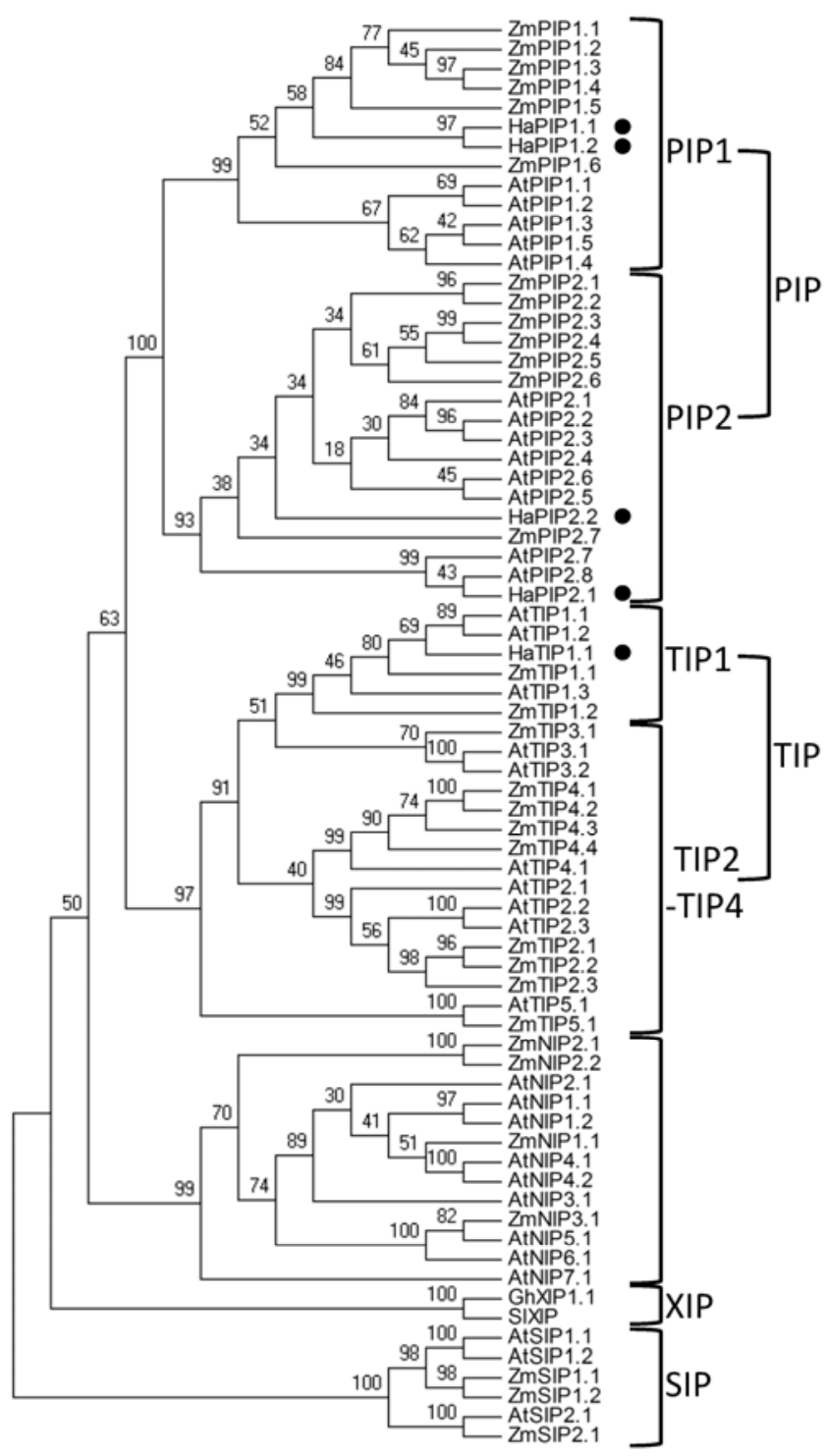


intrinsic proteins (MIP) was established according to their related Arabidopsis proteins (Johanson et al. 2001).

The HaPIP1; 1 cDNA sequence (GenBank accession number JF491349) encodes a protein of 290 amino acids, with an expected molecular weight of $31.1 \mathrm{kDa}$, that has $96 \%$ identity with GhPIP1;7 of Gossypium hirsutum (DAA33861.1; $e=9 \mathrm{e}-149$ ). The HaPIP1;2 cDNA sequence (GenBank accession number
JF491350), which is incomplete at its $5^{\prime}$ end, has $92 \%$ identity with GhPIP1;1 of $G$. hirsutum (ABK60194.1; $e=4 \mathrm{e}-109$ ).

HaPIP2; 1 cDNA (GenBank accession number JF491351) encodes a predicted protein of 279 amino acids, with an expected molecular weight of $29.8 \mathrm{kDa}$, that has $89 \%$ identity with VvPIP2;2 of Vitis vinifera (ABN14351.1; $e=1 \mathrm{e}-142$ ), while $H a P I P 2 ; 2$ cDNA sequence (GenBank accession number

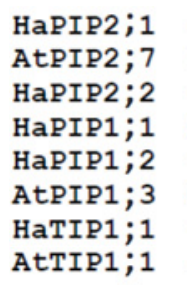

HaPIP2; 1 AtPIP2;7 HAPIP2;2 HaPIP1;1 HaPIP1;2 AtPIP1;3 HaTIP1; 1 AtTIP1; 1

HaPIP2 ; 1 AtPIP2; 7 HaPIP2; 2 HaPIP1; 1 HaPIP1; 2 AtPIP1; 3 HaTIP1; 1 AtTIP1; 1

HaPIP2;1
AtPIP2;7
HaPIP2;2
HaPIP1;1
HaPIP1;2
AtPIP1;3
HaTIP1;1
AtTIP1;

HaPIP2; 1 AtPIP2; 7 HaPIP2; 2 HaPIP1; 1 HaPIP1;2 AtPIP1; 3 HaTIP1; 1 AtTIP1; 1

HaPIP2; 1 AtPIP $2 ; 7$ HaPIP $2 ; 2$ HaPIP1 ; 1 HAPIP1; 2 AtPIP1;3 HaTIP1; 1 -AtTIP1; 1 --

Fig. 2. Alignment of the deduced amino acid sequences of HaTIP1;1 (ADU25490), HaPIP1;1 (JF491349), HaPIP1;1 (JF491350), HaPIP2;1 (JF491351), and HaPIP2;2 (JF491352) from Helianthemum almeriense with three Arabidopsis thaliana aquaporins: AtPIP1;3 (NP_171668.1), AtPIP2;7 (NP_195236.1), and AtTIP1;1 (P25818). Sequences were aligned using the ClustalW program. Amino acid numbers are shown on the right. Light blue indicates the residues that are identical in all sequences analyzed. Red boxed regions are predicted to form transmembrane domains, the NPA motifs are shaded yellow and residues conserved only in PIP family are shaded light green. Residues of serine shaded red represent possibly sites of phosphorylation while residues of histidine involved in $\mathrm{pH}$ sensing are shaded light purple. Black boxes indicate ar/R (aromatic/arginine) filters (H2, H5, LE1, and LE2). 
JF491352) encodes a protein of 281 amino acids, with an expected molecular weight of $30.0 \mathrm{kDa}$, that has $87 \%$ identity with JrPIP2;2 of Junglans regia (AAO39008.1; $e=4 \mathrm{e}-141)$.

The HaTIP1;1 sequence (GenBank accession number HQ234609) encodes a predicted protein of 252 amino acids, with an expected molecular weight of $25.9 \mathrm{kDa}$, that shows 88\% identity with HbTIP of Hevea brasiliensis (ACX37541.1; $e=1 \mathrm{e}-123)$.

All these $H$. almeriense AQP contain the MIP family signature sequence SGxHxNPAVT, which is repeated in the second half of the protein as GxxxNPARSxG in PIP (Zardoya 2005) (Fig. 2). The PIP proteins contain, as expected, His residues involved in $\mathrm{pH}$ sensing (Fischer and Kaldenhoff 2008; Luu and Maurel 2005; Törnroth-Horsefield et al. 2006), Ser residues in loop B, and, in the amino terminal only in PIP2, possible targets for phosphorylation (Johansson et al. 1998).

\section{Water, $\mathrm{CO}_{2}$ and $\mathrm{NH}_{3}$ permeability.}

Function of the identified AQP gene products was addressed by yeast assay experiments. HaTIP1;1 and HaPIP2.;1 showed a high water permeability coefficient $\left(P_{f}=7.2 \pm 1.6 \times 10^{-2}\right.$ and $10.9 \pm 2.8 \times 10^{-2} \mathrm{~cm} \mathrm{~s}^{-1}$, respectively). The $P_{f}$ of the spheroplast membranes increased 18- and 27-fold in yeast expressing HaTIP1;1 and HaPIP2;1, respectively, over the control (Fig. $3 \mathrm{~A})$. Yeast expressing HaPIP1; 1 had a $P_{f}$ of $1.2 \pm 0.3 \times 10^{-2}$ $\mathrm{cm} \mathrm{s}^{-1}$, similar to that of yeast grown in glucose (not induced) (Fig. 3A). In the $\mathrm{CO}_{2}$ transport analysis, yeast cells expressed a tobacco carbonic anhydrase in addition to the AQP. Only HaPIP1;1 $\left(2.7 \pm 0.3 \times 10^{-2} \mathrm{~cm} \mathrm{~s}^{-1}\right)$ significantly increased intracellular acidification rates in a $\mathrm{CO}_{2}$ gradient above controls (Fig. 3B). In contrast, HaTIP1;1 and HaPIP2;1 (1.6 $\pm 0.2 \times$ $10^{-2}$ and $2.0 \pm 0.3 \times 10^{-2} \mathrm{~cm} \mathrm{~s}^{-1}$, respectively) were not functional in this respect because their $P_{\mathrm{CO} 2}$ was not statistically different from the control (Fig. 3B). Only HaTIP1;1 showed a significant increase in $P_{N H 3}\left(4.1 \pm 0.4 \times 10^{-5} \mathrm{~cm} \mathrm{~s}^{-1}\right)$, which was 15 times larger than in the control and spheroplasts expressing other HaPIP (Fig. 3C).

\section{M colonization.}

The percentage of total colonization differed significantly between water treatments. Inoculated plants under drought stress presented a significantly higher root $\mathrm{M}$ colonization than wellwatered (WW plants (Table 1). The three M types were found under both irrigation regimes, and a wide range of intra- and intercellular hyphae were observed. However, the predominant type of mycorrhiza and the relative proportion among types were different. In the M-drought-stressed (DS) roots, the main $M$ type was endomycorrhiza followed by ectendo- and ectomycorrhiza without mantle, whereas the roots of M-WW plants presented ectendomycorrhiza as the principal type of colonization, with a low percentage of endomycorrhiza type (Table 1). Noninoculated control plants did not show any $\mathrm{M}$ colonization (data not shown).

\section{Plant growth and leaf mineral and pigment concentration.}

Irrigation treatment did not influence the concentration of chlorophylls $(\mathrm{a}+\mathrm{b})$. However, the $\mathrm{M}$ status had a significant effect on chlorophyll concentration, $M$ plants presenting a $36 \%$ increase above NM plants as an average of the two water treatments (Table 2). N, P, and $\mathrm{K}$ leaf concentrations were similar in all treatments (Table 2).

\section{Plant water status and gas exchange measurements.}

The combined effects of drought stress and $M$ inoculation on plant water status are shown in Table 2. Shoot water potential $(\Psi)$ was statistically different between irrigation treatments but not between $M$ inoculation treatments. The lowest $\Psi$ was measured in NM-DS plants $(-2.4 \mathrm{MPa})$, while the highest was found in M-WW plants (-0.8 MPa).

A similar behavior was observed for gas exchange parameters (Table 2). Net photosynthetic rate $(A)$ and stomatal conductance $\left(g_{s}\right)$ were significantly lower values under drought stress than
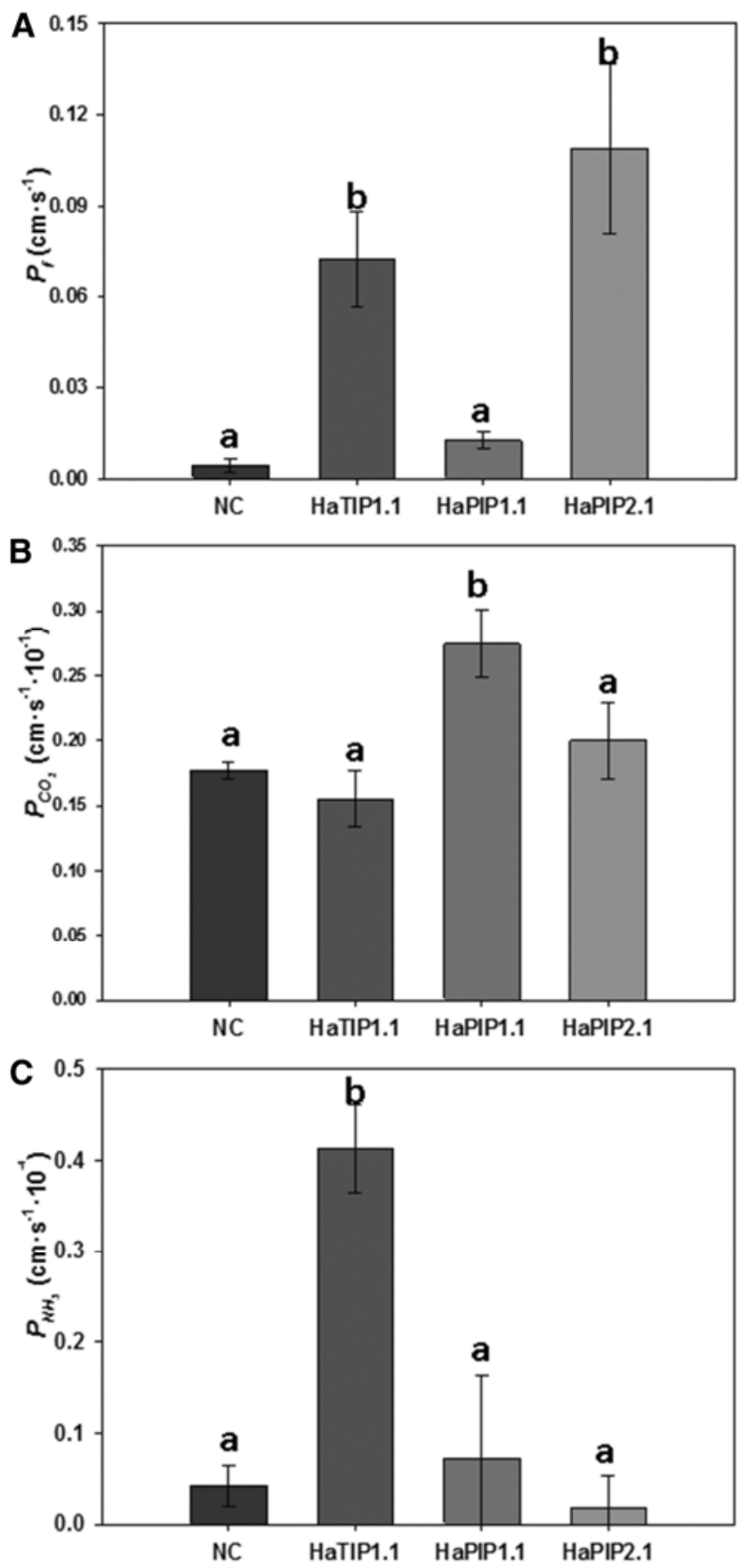

Fig. 3. Effect of HaTIP1;1, HaPIP1;1, and HaPIP2;1 expression on $\mathrm{CO}_{2}$, $\mathrm{NH}_{3}$, or water permeability of yeast plasma membranes. A, Water permeability. HaTIP1;1, HaPIP1;1, and HaPIP2;1 expressed in yeast cells and noninduced (negative control $[\mathrm{NC}]$ ). Bars show the water permeability coefficient $\left(P_{f}\right)$ means \pm standard error $(n=6)$. $\mathbf{B}, \mathrm{CO}_{2}$-triggered intracellular acidification of yeast. HaTIP1;1, HaPIP1;1, and HaPIP2;1 expressed in yeast cells and NtAQP1-3 helix protein (NC). In all cases, the cells also expressed the tobacco carbonic anhydrase. Bars show the $P_{\mathrm{CO} 2}$ means \pm standard error of $\mathrm{CO}_{2}$ permeability coefficient $\left(P_{\mathrm{CO} 2}\right)(n=6)$. $\mathbf{C}$, Intracellular alkalinization of yeast. HaTIP1;1, HaPIP1;1, and HaPIP2;1 expressed in yeast cells and noninduced (NC). Bars show the $P_{N H 3}$ means \pm standard error of $\mathrm{NH}_{3}$ permeability coefficient $\left(P_{N H 3}\right)(n=6)$. $P$ values for allocation to different significance groups (indicated by different letters) were $P<0.001$, as determined by analysis of variance and a Tukey's test. 
under WW conditions (Table 2). For both gas exchange parameters, these differences were larger in NM than in M plants, whereby $A$ in NM-DS plants was 2.2 -fold lower than in NMWW whereas, under drought stress, $A$ in $\mathrm{M}$ plants was 1.8 -fold lower with respect to M-WW plants (Table 2). The $g_{s}$ values in NM-DS plants were 3.0-fold lower than in M-WW plants but, in M-DS plants, $g_{s}$ decreased 1.5 -fold with respect to $\mathrm{M}-\mathrm{WW}$ plants (Table 2). Intrinsic water-use efficiency (WUE $E_{\text {intrinsic }}$ ) was similar in all treatments (approximately $70 \mu \mathrm{mol} \mathrm{CO}_{2} \mathrm{~mol}^{-1}$ $\mathrm{H}_{2} \mathrm{O}$ ), with the exception of NM-WW plants, where it was $38 \%$ lower compared with M-WW plants (Table 2).

\section{AQP expression.}

The expression of five AQP from $H$. almeriense and one AQP from T. claveryi was measured in leaves and roots (Fig. 4; Supplementary Table 1). For two of them, expression was significantly affected by $\mathrm{M}$ status or irrigation treatment. The expression of HaPIP1;1 showed an increase in NM roots with respect to $M$ roots, regardless of irrigation treatment. In the case of $\mathrm{HaPIP} 1 ; 2$, roots of WW plants presented higher level of expression than DS plants, regardless of $\mathrm{M}$ status. The gene expression levels between leaves and roots were compared but no significant differences were observed (data not shown).
In addition, significant correlations were observed between the expression of some AQP and gas exchange parameters such as $A$ and $g_{s}$ (Table 3 ). Most of the significant correlations observed were negative, implying that the lower the $A$ or $g_{s}$ values, the greater the expression of these AQP. NM-DS plants showed the highest number of correlations $(n=6)$ with AQP expression in roots and leaves. M-DS plants presented four correlations with AQP expression in roots only, including TcAQP1. NM-WW plants presented only two correlations and M-WW plants did not show any correlation.

\section{DISCUSSION}

\section{M colonization of $H$. almeriense under irrigation and drought stress.}

$\mathrm{M}$ associations may affect water transport by altering plant morphological characteristics (Calvo-Polanco et al. 2008) and, possibly, through a direct contribution of the hyphal network to water flow (Marjanović and Nehls 2008). One of the common explanations of improved water uptake by $\mathrm{M}$ compared with NM plants (Boyd et al. 1986) is the increased absorbing surface induced by hyphae growing in the soil, combined with the fungal capability to take up water from soils with a low

Table 1. Percentages of total colonization and different types of mycorrhizal colonization in Helianthemum almeriense plants grown under greenhouse conditions with different irrigation treatments ${ }^{\mathrm{z}}$

\begin{tabular}{lcccc}
\hline Water-treatment & Colonization(\%) & Endomycorrhiza(\%) & Ectendomycorrhiza(\%) & Ectomycorrhiza(\%) \\
\hline Drought stressed & $54.3 \pm 5.5 \mathrm{~b}$ & $53.5 \pm 7.5 \mathrm{~b}$ & $34.7 \pm 7.2 \mathrm{~b}$ & $11.8 \pm 4.8 \mathrm{~b}$ \\
Well Watered & $34.5 \pm 3.7 \mathrm{a}$ & $15.0 \pm 4.9 \mathrm{a}$ & $51.5 \pm 6.8 \mathrm{a}$ & $33.5 \pm 6.4 \mathrm{a}$ \\
\hline
\end{tabular}

${ }^{\mathrm{z}}$ Data were subjected to $\chi^{2}$ analysis. Different letters indicate significant differences $(P<0.001)$ according to Bonferroni correction. Values are the percentage \pm confidence interval at $95 \%$.

Table 2. Fresh weight (FW) of whole plant (shoot + root), chlorophyll content (Chl) $\left(\mu \mathrm{g} \mathrm{g}^{-1}\right.$ leaf), water potential $(\Psi)$ of 4-cm shoots, net photosynthesis $(A)$ $\left(\mu \mathrm{mol} \mathrm{CO} \mathrm{CO}_{2} \mathrm{~m}^{-1}\right)$, stomatal conductance $\left(g_{s}\right)\left(\mathrm{mmol} \mathrm{H} \mathrm{H} \mathrm{m}^{-2} \mathrm{~s}^{-1}\right)$, intrinsic water use efficiency (WUE) $\left(\mu \mathrm{mol} \mathrm{CO}_{2} \mathrm{~mol}^{-1} \mathrm{H}_{2} \mathrm{O}\right)$, and leaf mineral concentration of N, P, and K of mycorrhizal (M) and nonmycorrhizal (NM) Helianthemum almeriense plants under drought-stressed (DS) or well-watered (WW) conditions ${ }^{\mathrm{Z}}$

\begin{tabular}{|c|c|c|c|c|c|c|c|c|c|c|c|c|}
\hline Plants & $\begin{array}{l}\text { FW } \\
(\mathrm{g})\end{array}$ & Chl $(\mathbf{a}+\mathbf{b})$ & $\begin{array}{c}\Psi \\
(\mathbf{M P a})\end{array}$ & $A$ & $g_{s}$ & WUE & $\begin{array}{c}\text { N root } \\
(\%)\end{array}$ & $\begin{array}{c}\text { N leaves } \\
(\%)\end{array}$ & $\begin{array}{c}\text { P root } \\
(\%)\end{array}$ & $\begin{array}{c}P \text { leaves } \\
(\%)\end{array}$ & $\begin{array}{c}\text { K root } \\
(\%)\end{array}$ & $\begin{array}{c}\text { K leaves } \\
(\%)\end{array}$ \\
\hline
\end{tabular}

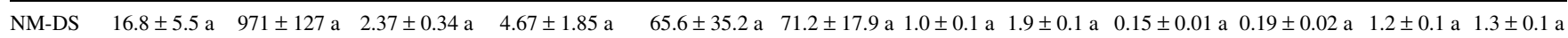
M-DS $\quad 15.2 \pm 5.4$ a $1,319 \pm 292$ b $\quad 1.90 \pm 0.29$ a $\quad 7.92 \pm 2.79$ ab $\quad 112.8 \pm 41.9$ a $\quad 70.2 \pm 13.0$ a $0.9 \pm 0.1$ a $\quad 2.0 \pm 0.2$ a $\quad 0.14 \pm 0.01$ a $0.18 \pm 0.01$ a $\quad 1.0 \pm 0.1$ a $\quad 1.1 \pm 0.1$ a

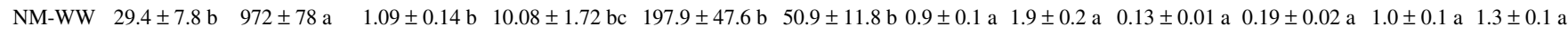

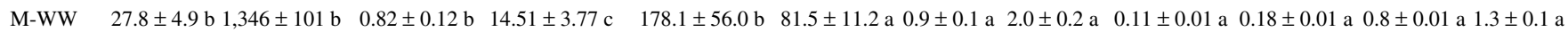

${ }^{\mathrm{z}}$ Different letters indicate significant differences $(P<0.05)$ by analysis of variance and Tukey test. Values show means $(n=5) \pm$ standard error.

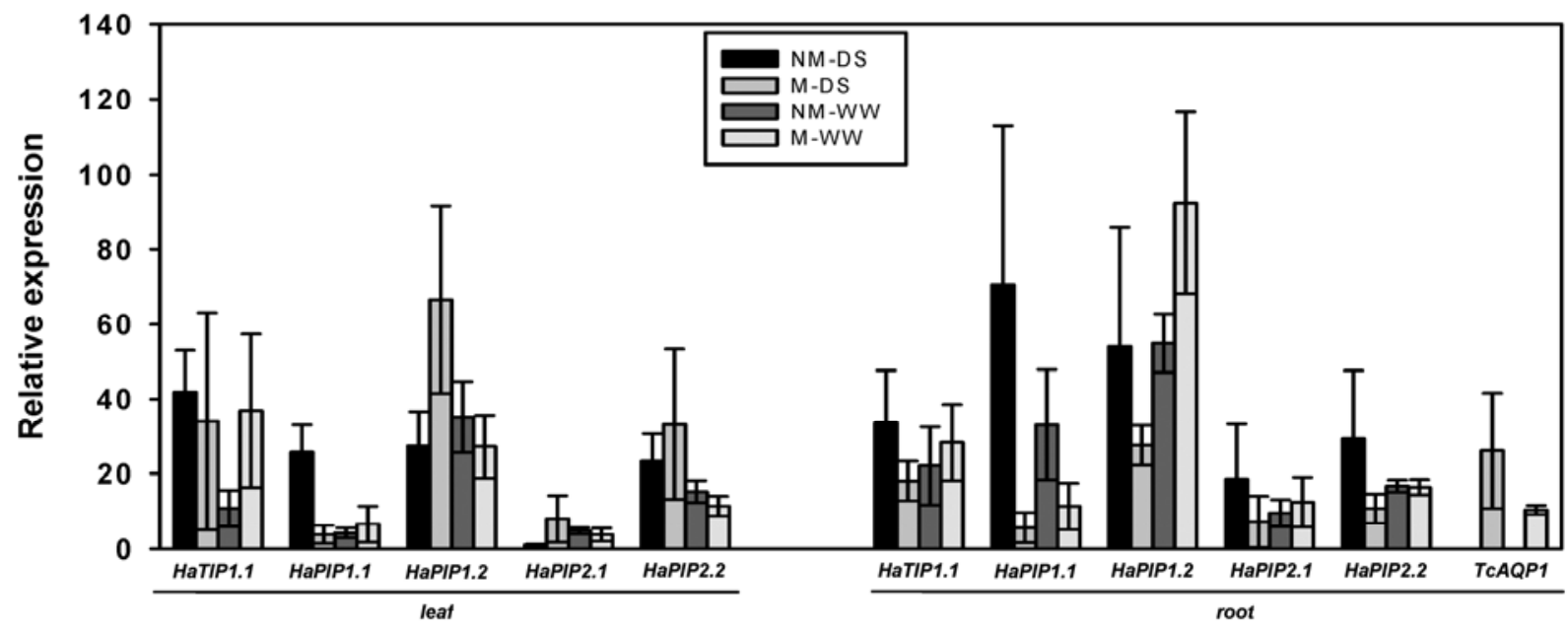

Fig. 4. Relative expressions of five plant aquaporins and the fungal aquaporin assessed by reverse-transcriptase quantitative polymerase chain reaction in mycorrhizal (M) and nonmycorrhizal (NM) Helianthemum almeriense plants under drought-stressed (D-S) or well-watered (W-W) conditions. Data for each condition are presented as the mean and were obtained from three biological and three technical replicates. Bars show the standard error. Data were subjected to analysis of variance but no significant differences were detected $(P<0.05)$. 
water potential (Lehto and Zwiazek 2011; Mexal and Reid 1973; Theodorou 1978; Theodorou and Bowen 1970).

$H$. almeriense $\mathrm{M}$ plants subjected to drought stress presented a higher colonization percentage than in watered plants, confirming that this symbiosis is responsive to drought stress, which modifies not only the total colonization of roots but also the main type of mycorrhization. Fungal hyphae of ectomycorrhiza do not penetrate the cell wall of the root and, therefore, one way of increasing hydraulic conductance in roots is by decreasing the water flow resistance of the apoplastic pathway (Muhsin and Zwiazek 2002). However, apoplastic water flow in roots is restricted by the presence of suberized barriers such as the exo- or endodermis and water is then forced to follow the cell-to-cell pathway (symplastic and transmembrane) (Steudle and Peterson 1998). M-DS plants of H. almeriense/T. claveryi presented higher intracellular colonization than $\mathrm{M}$ WW plants. Intracellular hyphae could favor the passage of water to the transcellular pathway because they would release the water directly at the $\mathrm{M}$ interface, thus avoiding the need to cross the root cell wall.

Several authors have discussed the structural versatility of Helianthemum and Terefezia mycorrhiza to form endo-, ectendo-, and ectomycorrhizas, focusing primarily on nutritional factors such as the availability of phosphorus (Fortas and Chevalier 1992; Kagan-Zur et al. 1994; Kovács et al. 2003; Roth-Bejerano et al. 1990; Zaretsky et al. 2006) or iron (RothBejerano et al. 1990), culture conditions (Gutiérrez et al. 2003), and even the interaction between phosphorus and intrinsic factors such as sensitivity to auxins (Zaretsky et al. 2006). In contrast, other factors such as water availability have not been considered in spite of the wide adaptation to arid conditions which desert truffles present. According to Navarro-Ródenas and associates (2012a), there is no clear cut-off between the three main types of mycorrhiza organization and this symbiosis should be considered as an ectendomycorrhizal continuum, in which water availability efficiently modifies the relative amount between intra- and intercellular hyphae in this continuum. Our results confirm that the scarcer the water, the more intracellular colonization becomes.

DS plants showed lower $A$ and $g_{s}$ values, more negative $\Psi$, and lower growth than WW plants; however, for all the tested parameters, NM plants suffered the drought-stress conditions more evidently than $\mathrm{M}$ plants. It has been hypothesized that the presence of a fungal sink may stimulate the rate of $\mathrm{C}$ assimilation (Tinker et al. 1994). However, evidence in support of this hypothesis remains limited due to conflicting results (Nehls et al. 2010; Wright et al. 2000). The $A$ values decreased less in $H$. almeriense M-DS than NM-DS plants (Table 2). The higher $\mathrm{CO}_{2}$ assimilation in $\mathrm{M}$ plants may be explained by their higher chlorophyll content (Azcon-Bieto and Talón 2008), regardless of the water supply (Table 2). One of the most common responses to water deficit in plants is stomatal closure and increased of $W U E_{\text {intrinsic }}$ (Sánchez-Díaz and Aguirreolea 2008a). In our assay, DS plants (both $\mathrm{M}$ and $\mathrm{NM}$ ) showed higher $W U E_{\text {intrinsic }}$ values than NM-WW. However, M-WW plants showed a $W U E_{\text {intrinsic }}$ similar to DS plants. Thus, mycorrhiza exert a certain control of transpiration, allowing $\mathrm{M}$ plants to maintain, without water restrictions, higher levels of $W U E_{\text {intrinsic }}$, with values comparable with plants subjected to drought.

\section{Functional characterization of $\boldsymbol{H}$. almeriense AQP.}

Transmembrane water movement is controlled by the abundance and activity of AQP (Maurel et al. 2008) and, for this reason, we isolated five MIP from $H$. almeriense, including one TIP and four PIP. The functional analysis of three of the isolated AQP, representing the three main MIP families present in plants (PIP1, PIP2, and TIP), revealed different putative functions. PIP AQP behaved differently with regard to water and $\mathrm{CO}_{2}$ uptake when expressed in the yeast membrane. HaPIP1;1 induced a significant increase in $\mathrm{CO}_{2}$ flow rates but showed a very low enhancement of $P_{f}$ (nine times lower) compared with HaPIP2;1 which, in contrast, displayed no statistically significant differences from the control as concerns $\mathrm{CO}_{2}$ transport.

Several reports have shown that PIP1 AQP, expressed in heterologous systems, induce very low or undetectable increases in membrane water permeability (Chaumont et al. 2000; Kammerloher et al. 1994; Otto et al. 2010; Secchi et al. 2007, 2009). Thus, proteins from the PIP1 family usually exhibit little or no water channel activity when expressed in oocytes, although they have been reported to interact with PIP2 isoforms and to increase their membrane permeability (Fetter et al. 2004; Temmei et al. 2005; Zelazny et al. 2007). This suggests that PIP1 isoforms play a role in water permeability, possibly interacting with PIP2 isoforms. In the present study, HaPIP1;1 showed a significantly different expression level in the roots depending on $M$ status. Therefore, although HaPIP1;1 did not show water permeability when expressed alone, its expression changes could affect transmembrane water flow by interacting with an HaPIP2 isoform, in a similar way as observed for other plant PIP1 proteins.

However, we must not lose sight of the capacity of HaPIP1;1 to increase $\mathrm{CO}_{2}$ conductivity. The concept of $\mathrm{CO}_{2}$ diffusion through the plasma membrane has been changed by cooporins (Terashima et al. 2006). Several studies, such as inhibition with mercury (Terashima and Ono 2002) and transgenic plants with altered AQP expression systems (Flexas et al. 2006; Hanba et al. 2004; Uehlein et al. 2003, 2008), have demon-

Table 3. Correlations between net photosynthesis $(A)$ or stomatal conductance $\left(g_{s}\right)$ and aquaporin expression of mycorrhizal (M) and nonmycorrhizal (NM) Helianthemum almeriense plants under drought-stressed (DS) or well-watered (WW) conditions ${ }^{\mathrm{z}}$

\begin{tabular}{|c|c|c|c|c|c|c|c|c|c|c|c|}
\hline \multirow[b]{2}{*}{ Plants } & \multicolumn{5}{|c|}{ Leaf } & \multicolumn{6}{|c|}{ Root } \\
\hline & HaTIP1.1 & HaPIP1.1 & HaPIP1.2 & HaPIP2.1 & HaPIP2.2 & HaTIP1.1 & HaPIP1.1 & HaPIP1.2 & HaPIP2.1 & HaPIP2.2 & TcAQP1 \\
\hline \multicolumn{12}{|l|}{ NM-DS } \\
\hline$A$ & $-0.983^{*}$ & -0.692 & -0.108 & $0.888 *$ & -0.617 & $-0.935^{*}$ & -0.385 & 0.478 & 0.250 & 0.199 & $\ldots$ \\
\hline $\begin{array}{c}g_{s} \\
\text { M-DS }\end{array}$ & $-0.968^{*}$ & $-0.946^{*}$ & -0.233 & 0.573 & -0.760 & $-0.953^{*}$ & -0.716 & 0.555 & 0.387 & 0.103 & $\ldots$ \\
\hline$A$ & -0.024 & 0.327 & 0.119 & -0.128 & 0.100 & -0.792 & 0.566 & $-0.891 *$ & 0.548 & 0.846 & $-0.889 *$ \\
\hline$g_{s}$ & -0.164 & 0.643 & 0.024 & -0.270 & -0.116 & $-0.922 *$ & 0.732 & $-0.952 *$ & 0.175 & 0.776 & -0.755 \\
\hline \multicolumn{12}{|l|}{ NM-WW } \\
\hline$A$ & -0.471 & -0.327 & 0.355 & 0.157 & 0.527 & -0.420 & -0.571 & $-0.901 *$ & -0.226 & $-0.882^{*}$ & $\ldots$ \\
\hline $\begin{array}{l}g_{s} \\
\mathrm{M}-\mathrm{WW}\end{array}$ & -0.688 & 0.473 & 0.466 & 0.218 & 0.601 & -0.781 & 0.116 & -0.666 & -0.422 & -0.826 & $\ldots$ \\
\hline$A$ & 0.259 & 0.403 & 0.491 & 0.024 & 0.536 & 0.247 & 0.563 & -0.247 & -0.503 & -0.250 & -0.863 \\
\hline$g_{s}$ & 0.517 & 0.677 & 0.655 & 0.988 & 0.681 & 0.098 & 0.497 & -0.381 & -0.550 & -0.358 & -0.866 \\
\hline
\end{tabular}

${ }^{\mathrm{z}}$ Values are the Pearson's coefficients; * indicates the level of significance at $P \leq 0.05$. 
strated that PIP1 proteins can alter leaf mesophyll conductance to $\mathrm{CO}_{2}\left(\mathrm{~g}_{\mathrm{m}}\right)$ and assimilation capacity. One of the most studied cooporins is NtAQP1 from tobacco, which also increases $\mathrm{CO}_{2}$ conductivity when expressed in yeast (Otto et al. 2010). Given that HaPIP $1 ; 1$ enhances the $\mathrm{CO}_{2}$ permeability of yeast membranes, we would expect it to increase $\mathrm{g}_{\mathrm{m}}$ in $H$. almeriense leaves which, in turn, would increase leaf intercellular $\mathrm{CO}_{2}$ concentration and decrease $g_{s}$. This hypothesis is corroborated by the significant negative correlation between $\mathrm{HaPIP} 1 ; 1$ expression in leaves and $g_{s}$ values in NM-DS plants.

HaTIP1;1 facilitated the transmembrane transport of water and $\mathrm{NH}_{3}$ in the yeast system and presents a histidine/isoleucine/alanine/arginine signature in the constriction region similar to other TIP (Jahn et al. 2004). Recent studies in mycorrhiza have highlighted the potential for the direct transfer of ammonia from fungal to plant cells (Chalot et al. 2006) and suggested that attention should also be devoted to nonspecific channels such as AQP.

\section{Effects of $M$ colonization and drought stress on the expression of $\boldsymbol{H}$. almeriense AQP.}

In this experiment, a nutrient solution was supplied to NM plants in order to obtain plants of comparable size, as is routinely done in M research (Porcel et al. 2004, 2006). Nutrient solution was added to the pots before start of the stress treatments (i.e., 30 days before harvest) and leaf mineral concentration of $\mathrm{M}$ and $\mathrm{NM}$ plants was not different; therefore, it is unlikely that different nutrient availability may have induced changes in gene expression. In roots, differences in expression between $\mathrm{M}$ and NM plants were only observed for HaPIP1;1, which was downregulated by $\mathrm{M}$ colonization. In leaves, on the contrary, we observed no effects of mycorrhization on AQP gene expression, suggesting that AQP expression changes are mediated by the direct interaction between plant and fungal cells. However, several negative correlations between PIP2 AQP expression and $g_{s}$ or $A$ values were detected, particularly in roots. The expression level of PIP2 AQP, which efficiently enhance transmembrane water transport in yeast membranes, is expected to control plasma membrane permeability. These negative correlations with gas exchange parameters could indicate a control of the expression of certain AQP by $A$ or $g_{s}$. In other words, when $A$ decreases, an increase in the expression of these AQP could act as a compensatory mechanism. In this sense, we observed that the number of positive and negative correlations in plants of each treatment were higher in the most stressful physiological status (DS). Therefore, some of the AQP analyzed in this study were only subjected to finetuned expression when conditions were sufficiently restrictive. We are aware that we only studied a few AQP within a family that presumably counts more than 20 members but those we isolated are probably highly expressed and could give a major contribution to transmembrane water transport in $H$. almeriense. More plant AQP should be studied to obtain a general AQPbased interpretation of the physiological data. Several studies have compared AQP expression in DS and WW NM and M plants (Aroca et al. 2008; Krajinski et al. 2000; Lee et al. 2010; Porcel et al. 2006; Roussel et al. 1997; Ruiz-Lozano 2003). Our results show a fine-tuned control of AQP expression in roots of $H$. almeriense, which might be important to improve root hydraulic conductance. Lovisolo and associates (2007) proposed that olive tree, a species adapted to arid environments, may have developed mechanisms of fine-tuned root AQP expression to improve water uptake. The upregulation of AQP could be a way to increase water flow to specific organs that are crucial for plant survival during drought or necessary for a rapid recovery upon rehydration of the plant (Alexandersson et al. 2005) whereas, in general, downregulation of AQP might be a way to minimize water loss and maintain turgor in leaves (Porcel et al. 2006).

Greater attention should be focused on $T$. claveryi AQP expression. The expression of TcAQP1 appeared to be regulated by $A$, increasing its expression when $A$ decreased, but only in DS plants. In two different studies, we observed that free-living T. claveryi mycelium is able to sense and respond to water stress (Navarro-Ródenas et al. 2011) and that TcAQP1 expression shows a bimodal behavior with respect to external water stress, thus contributing to improve the drought-stress tolerance of the mycelium (Navarro-Ródenas et al. 2012b). However, the negative correlation with plant physiological parameters suggests that there is some communication between symbionts, so that the fungus responds to the plant's needs. Lee and associates (2010) suggested that the increase in hydraulic conductivity of root cortical cells of ectomycorrhizal plants could be a result of plant AQP-mediated water transport but that a role of fungal AQP should also be taken into account. The combination of high intracellular colonization in roots of M-DS plants, together with the fine-tuned expression of TcAQP1, could result in a morphophysiological adaptation of the $H$. almeriense/T. claveryi mycorrhiza to arid and semiarid conditions.

\section{MATERIALS AND METHODS}

\section{Biological materials, growth conditions, and experimental setup.}

Calcareous soil was collected from Zarzadilla de Totana

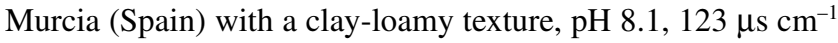
electrical conductivity, $1.2 \%$ organic carbon, $10.2 \mathrm{C} / \mathrm{N}$ ratio, and nutrient concentrations (ppm) of $\mathrm{P}, 20.7 ; \mathrm{Fe}, 4.4 ; \mathrm{Mn}$, $13.9 ; \mathrm{Cu}, 1.0$; and $\mathrm{Zn}, 1.5$. This soil was mixed with black peat, vermiculite, and sepiolite $(2: 2: 2: 1$ [vol/vol]) and sterilized by steaming $\left(100^{\circ} \mathrm{C}\right.$ for $1 \mathrm{~h}$ on three nonconsecutive days). The final $\mathrm{pH}$ of the mixture was 7.1.

$H$. almeriense seed-collected wild plants in the Zarzadilla de Totana area (Murcia, Spain) were scarified and surface sterilized with $10 \% \mathrm{H}_{2} \mathrm{O}_{2}(30 \mathrm{~min})$ and sown in Murashige and Skoog medium (Murashige and Skoog 1962) solidified with $8 \%$ agar. After 60 days of growth, seedlings were transferred to $230-\mathrm{ml}$ pots containing the above-described substrate. After 30 days, part of the plants were inoculated with approximately $10^{7}$ mature spores each, obtained from ascocarps collected in the same area under $H$. almeriense plants (Morte et al. 2008). Six weeks after inoculation, inoculated and noninoculated plants were transferred to 2.7-liter pots containing the same substrate. Plants were grown under greenhouse conditions with 55 to $57 \%$ relative humidity; day and night temperature of 23 to 26 and 11 to $15^{\circ} \mathrm{C}$, respectively; a photoperiod of $16 \mathrm{~h}$; and photosynthetic photon flux density maximum of $1,100 \mu \mathrm{mol} \mathrm{m}{ }^{-2} \mathrm{~s}^{-1}$, of which 300 were supplied by supplemental lights (sodium vapor, $400 \mathrm{~W}$; Gavita, Aalsmeer, The Netherlands).

Water stress was applied on part of the plants, 30 days before harvest, by controlling irrigation. Soil moisture was measured with Watermark tensiometers placed at $10 \mathrm{~cm}$ of depth in one pot per treatment. For the WW control treatment (receiving 0.3 liters/week), the soil matric potential $\left(\Psi_{\mathrm{m}}\right)$ was maintained between 0 and $-10 \mathrm{kPa}$ (container capacity) and, for the DS treatments (receiving $0.15 \mathrm{ml} /$ week), $\Psi_{\mathrm{m}}$ was maintained between -100 and $-120 \mathrm{kPa}$.

NM plants received $300 \mathrm{ml}$ of half-strength Compo Fertilizante Universal nutrient solution, three times before starting the drought-stress treatment. $\mathrm{M}$ plants did not receive nutrient solution. The aim of such fertilization was to obtain NM plants of similar size to the $\mathrm{M}$ plants tested in this assay.

The plants were harvested after 30 days from the start of the drought treatment. The soil was removed carefully from the 
roots with water. Fine roots and leaves were frozen in liquid nitrogen and stored at $-80^{\circ} \mathrm{C}$.

The experiment was set up as a two-by-two factorial with 10 replicate plants per each of four treatments: NM-WW, NMDS, M-WW, and M-DS. Replicate plants were arranged in randomized blocks.

\section{Analysis of M colonization, water status, and leaf composition.}

Fine frozen roots from three plants, randomly selected within each water treatment, were sectioned as previously described (Morte et al. 2010). All root sections were observed under an Olympus BH2 microscope and classified into one of the following M types: "ectomycorrhiza", with intercellular hyphae; "ectendomycorrhiza", with intracellular hyphae and intercellular hyphae; or "endomycorrhiza", when only intracellular hyphae were observed (Gutiérrez et al. 2003).

Midday $\Psi$ was measured immediately before harvest at 1200 to $1400 \mathrm{~h}$ on six plants randomly chosen within each treatment. To this aim, $4 \mathrm{~cm}$-long plant apices were cut with a razor blade and immediately placed in a pressure chamber (Soil Moisture Equipment Co; Santa Barbara, CA, U.S.A.) according to Scholander and associates (1965).

Leaf gas exchange measurements were taken at the same time. $A$ and $g_{s}$ were measured as previously described (Morte et al. 2010). $W U E_{\text {intrinsic }}$ was calculated as $A / g_{s}$.

Chlorophylls were extracted from $0.05 \mathrm{~g}$ of leaf tissue in a mortar at $4^{\circ} \mathrm{C}$ after suspension in $5 \mathrm{ml}$ of $80 \%$ aqueous acetone. The homogenate was then centrifuged at $10,000 \times g$ for $10 \mathrm{~min}$ and the absorbance at 470, 646, and $663 \mathrm{~nm}$ was measured. The concentrations of chlorophyll were calculated according to Coombs and associates (1985) and Wellburn (1994). Leaves and roots of five plants were briefly rinsed with deionized water, oven dried at $60^{\circ} \mathrm{C}$ for $72 \mathrm{~h}$, and ground to a fine powder. Tissue $\mathrm{P}, \mathrm{N}$, and $\mathrm{K}$ concentrations were determined by inductively coupled plasma optical emission spectrometry (Iris Intrepid II;
Thermo Electron Corporation, Marietta, OH, U.S.A.) after acid digestion.

\section{RNA isolation and isolation of AQP genes.}

RNA was isolated from frozen leaves and roots of five plants according to the protocol of Chang and associates (1993). The nucleic acid extract was treated with DNase (Promega, Madison, WI, U.S.A.) according to the manufacturer's instructions. The concentration of RNA was quantified by measuring the absorbance at $260 \mathrm{~nm}$ and its integrity was checked on agarose gels.

A reverse-transcription polymerase chain reaction (RT-PCR) strategy was used to identify partial AQP transcripts. cDNA was synthesized from $5 \mu \mathrm{g}$ of total RNA using oligo-(dT) ${ }_{15}$ (Promega) and Superscript reverse transcriptase (Invitrogen, Carlsbad, CA, U.S.A.).

Three different pairs of primers were used for amplification: PIP type (PIP-S and PIP-AS) (Secchi et al. 2007), degenerate primers for PIP-type (PIP-for and PIP-rev) (Porcel et al. 2006), and degenerate primers for TIP-type (TIP-S and TIP-AS) (Secchi et al. 2007).

PCR was performed using recombinant Taq DNA polymerase (Invitrogen), according to the manufacturer's instructions. The PCR cycles were: 1 cycle of $95^{\circ} \mathrm{C}$ for $9 \mathrm{~min} ; 35$ cycles of $94^{\circ} \mathrm{C}$ for $45 \mathrm{~s}, 55,49$, and $52^{\circ} \mathrm{C}$ for PIP-S/AS, PIP-for/rev, and TIP-S/AS, respectively, for $45 \mathrm{~s}$, and $72^{\circ} \mathrm{C}$ for $1 \mathrm{~min}$; and a final step at $72^{\circ} \mathrm{C}$ extended for $7 \mathrm{~min}$. The amplification products were subjected to $2 \%$ agarose gel electrophoresis and stained with SYBR Safe (Invitrogen). DNA from bands of the expected product length were cloned by ligation into the pGEM-T Easy vector (Promega) and the product was used to transform Escherichia coli JM109 high-efficiency competent cells (Promega). Positive clones were screened by PCR and subcultured. Plasmid DNA was isolated using QIAprep Spin miniprep kit (Qiagen, Hilden, Germany). The purified plasmids were sequenced on an ABI Prism 310 platform (Applied Biosystems, Foster City, CA, U.S.A.) using the universal M13

Table 4. List of primers used

\begin{tabular}{|c|c|c|c|}
\hline Primer code & DNA sequence & Orientation $^{\mathrm{y}}$ & $\mathrm{Use}^{\mathrm{z}}$ \\
\hline HaPIP1.1+ & 5'-GTGAGCTCTCATCATGGTCCTT-3' & $\mathrm{S}$ & HaPIP1.1-3' RACE \\
\hline HaPIP1.1- & 5'-CCAAGTGGACCAAGAAGACG-3' & AS & HaPIP1.1-5' RACE \\
\hline HaPIP1.2+ & 5'-GAGAGCTCACTTCTTGGTCCTT-3' & $\mathrm{S}$ & HaPIP1.2-3' RACE \\
\hline HaPIP1.2- & 5'ATGAATCCCTTCACCACACC-3' & AS & HaPIP1.2-5' RACE \\
\hline HaPIP2.1+ & 5'-CTCAGTGTTTGGGAGCCATCT-3' & S & HaPIP2.1-3' RACE \\
\hline HaPIP2.1- & 5'-GTTTTAGTTGGTGGGGTTGC-3' & AS & HaPIP2.1-5' RACE \\
\hline HaPIP $2.2+$ & 5'-CTCAGTGTTTGGGAGCCATCT-3' & S & HaPIP2.2-3' RACE \\
\hline HaPIP2.2- & 5'-CCGGCTCTCAATATGTACTGG-3' & AS & HaPIP $2.2-5^{\prime}$ RACE \\
\hline HaTIP1.1+ & 5'-СTCTCCTCCGTGGAATTCTCTA-3' & S & HaTIP1.1-3' RACE \\
\hline HaTIP1.1- & 5'-GGCGATAATTCCGATATTGC-3' & AS & HaTIP1.1-5' RACE \\
\hline Anchor & 5'-GACCACGCGTATCGATGTCGAC-3' & $\ldots$ & $\ldots$ \\
\hline Oligo-(dT)-anchor & 5'-GACCACGCGTATCGATGTCGACTTTTTTTTTTTTTTTTV-3' & $\ldots$ & $\ldots$ \\
\hline HaTIP1.1for & 5'-TAGTAACTCCGGCCATGAGC-3' & $\mathrm{S}$ & HaTIP1.1 qPCR \\
\hline HaTIP1.1rev & 5'-CACAATAACAACAACTCCCA-3' & AS & HaTIP1.1 qPCR \\
\hline HaPIP1.1for & 5'-GATGGGTGATGATGATGAAGC-3' & S & HaPIP1.1 qPCR \\
\hline HaPIP1.1rev & 5'AGAAGGCGCATGGATAGAAG-3' & AS & HaPIP1.1 qPCR \\
\hline HaPIP1.2for & 5'-TCAGGACCGTTGATTTGATG-3' & S & HaPIP1.2 qPCR \\
\hline HaPIP1.2rev & 5'-CATCATGTAGGGCCCACTTAC-3' & AS & HaPIP1.2 qPCR \\
\hline HaPIP2.1for & 5'-TGCCTTTGTGTGTATGATGAAG-3' & $\mathrm{S}$ & HaPIP2.1 qPCR \\
\hline HaPIP2.1rev & 5'-TGATACAAGCCACCACCAGA-3' & AS & HaPIP2.1 qPCR \\
\hline HaPIP2.2for & 5'-TGCCCAAATGTAGCATTATCC-3' & S & HaPIP2.2 qPCR \\
\hline HaPIP2.2rev & 5'-GAGAGGAAATGAACTTCACATT-3' & AS & HaPIP2.2 qPCR \\
\hline TcAQP1for & 5'-AGATCGGTTACGGCATTCAG-3' & S & TcAQP1 qPCR \\
\hline TcAQP1rev & 5'-CCAGGAAAATCGAAACCCTA-3' & AS & TcAQP1 qPCR \\
\hline TcElonfacfor & 5'-TCCGTTAAGGAAATTCGTCG-3' & $\mathrm{S}$ & TcEF1-alfaII qPCR \\
\hline TcElonfacrev & 5'-GTCCAGGGTGGTTCATCAAG-3' & AS & TcEF1-alfaII qPCR \\
\hline Ha18Sfor & 5'-CCTGCGGCTTAATTTGACTC-3' & $\mathrm{S}$ & Ha18S qPCR \\
\hline Ha18Srev & 5'-AACTAAGAACGGCCATGCAC-3' & AS & Ha18S qPCR \\
\hline
\end{tabular}

\footnotetext{
${ }^{\mathrm{y}}$ Orientation of the oligonucleotide relative to corresponding amino acid sequence: $\mathrm{S}=$ sense and AS = antisense.
}

${ }^{\mathrm{z}} \mathrm{RACE}=$ rapid amplification of $\mathrm{cDNA}$ ends and $\mathrm{qPCR}=$ quantitative polymerase chain reaction. 
primers. Similarity searches were carried out using the tBlastx software available on-line from the National Centre for Biotechnology Information. Several plasmids containing a putative AQP were obtained ( $p H a P I P 1 ; 1, p H a P I P 1 ; 2, p H a P I P 2 ; 1$, $p H a P I P 2 ; 2$, and $p H a T I P 1 ; 1)$. Their sequence information was then used to design specific primers for full-length gene cloning by rapid amplification of cDNA ends (RACE). The $5^{\prime}$ and $3^{\prime}$ first-strand cDNA were obtained and amplified using the 2nd Generation Roche 5'/3' RACE Kit according to the manufacturer's instructions. The primers used in addition to the adapter-specific primers are shown in Table 4. The $3^{\prime}$ and $5^{\prime}$ full-length nucleotide sequences of four $H$. almeriense AQP and one $5^{\prime}$ incomplete $(\mathrm{HaPIP} 1 ; 2)$ sequence were determined and submitted to Gen-Bank (accession numbers JF491349 [HaPIP1;1], JF491350 [HaPIPl;2], JF491351 [HaPIP2;1], JF491352 [HaPIP2;2], and HQ234609 [HaTIP1;1]).

\section{Sequence analysis.}

The deduced amino acid sequences of HaTIP1;1, HaPIP1;1, HaPIP1;2, HaPIP2;1, and HaPIP2;2 were aligned with other MIP encoding sequences using the program ClustalW. A phylogenetic analysis of the five HaMIP with the complete set of Arabidopsis thaliana $(n=35)$ and Zea mays $(n=36)$ MIP and two representatives of XIP from $G$. hirsutum and Solanum lycopersicum (Chaumont et al. 2001; Johanson et al. 2001; Park et al. 2010; Sade et al. 2009) was constructed using the neighbor-joining method and drawn using MEGA4. THMM was used for transmembrane domain prediction, NetPhos 2.0 Server (Blom et al. 1999) for the identification of phosphorylation sites, and the Compute $\mathrm{pI} / \mathrm{Mw}$ tool for calculating the molecular weights.

\section{Subcloning and yeast expression.}

The complete open reading frames of $H$. almeriense HaTIP1;1, HaPIP1;1, and HaPIP2;1 were inserted into pYesDEST52 (Invitrogen) yeast expression vector using Gateway (Invitrogen) technology. Saccharomyces cerevisiae strain SY1 (Mat $\alpha$, ura3-52, leu2-3,112, his4-619, sec6-4 ${ }^{\text {ts }}$, and GAL2) (Nakamoto et al. 1991) containing the pGREG505-2 $\mu$ vector with the Nicotiana tabacum carbonic anhydrase (GenBank accession number M94135) (Otto et al. 2010) was transformed by electroporation (Gene Pulser Xcell Electroporation System; Bio-Rad, Hercules, California, U.S.A.). Selection was based on ura3 and leu2 complementation. Transformed yeasts were cultured in glucose-containing synthetic complete broth medium without Ura/Leu for $20 \mathrm{~h}\left(225 \mathrm{rpm}, 30^{\circ} \mathrm{C}\right)$ and heterologous protein expression was induced by changing the medium carbon source to galactose and growing for $16 \mathrm{~h}\left(225 \mathrm{rpm}, 30^{\circ} \mathrm{C}\right)$.

$P_{f}$ was measured in yeast spheroplasts prepared as described by Fischer and Kaldenhoff (2008). The measurement were made in a stopped-flow spectrophotometer (SFM-300; BioLogic SAS, Claix, France) and, for calculations of $P_{f}$, Biokine software (Bio-Logic SAS) was used as described earlier (Navarro-Ródenas et al. 2012b). For controls, yeasts grown in glucose were used. The $P_{f}$ values were obtained for at least six independent induction experiments with an average of 20 measurements per experiment $(n \geq 120)$.

$\mathrm{CO}_{2}$ uptake was observed by intracellular acidification, monitoring the decrease in fluorescence in complete yeast cells loaded with fluorescein bisacetate as described by Fischer and Kaldenhoff (2008). The measurement were made in a stopped-flow spectrophotometer (SFM-300; Bio-Logic SAS) and, for calculations of $P_{\mathrm{CO} 2}$, Biokine software (BioLogic SAS) was used as described earlier (Navarro-Ródenas et al. 2012b). As controls, yeasts expressing the three amino-terminal helices of NtPIP2; 1 and carbonic anhydrase from tobacco were used (Otto et al. 2010). The $P_{\mathrm{CO} 2}$ values were obtained for at least six independent induction experiments with an average of 20 measurements per experiment $(n \geq 120)$.

$\mathrm{NH}_{3}$ conductivity measurements were made in yeast cells loaded with fluorescein bisacetate as described by Fischer and Kaldenhoff (2008). The measurement were made in a stoppedflow spectrophotometer (SFM-300; Bio-Logic SAS) and, for calculations of $P_{\mathrm{NH} 3}$, Biokine software (Bio-Logic SAS) was used as described earlier (Navarro-Ródenas et al. 2012b) The $P_{N H 3}$ values were obtained for at least six independent induction experiments with an average of 20 measurements per experiment $(n \geq 120)$.

\section{Quantitative real-time RT-PCR.}

Expression of HaTIP1;1, HaPIP1;1, HaPIP1;2, HaPIP2;1, HaPIP2;2, and TcAQP1 (JF491353) was studied by real-time PCR using an iCycler (Bio-Rad Laboratories). The primer sets used to amplify HaMIPS and TcAQP1 genes are shown in Table 4. Primers were designed in the $3^{\prime}$ untranslated region with Primer 3 v.0.4.0. Each $20-\mu l$ reaction contained $1 \mu \mathrm{l}$ of a dilution 1:10 of the cDNA, $200 \mathrm{nM}$ dNTPs, $10 \mu \mathrm{l}$ of QUANTiPROBES $2 \times$ (Biotools, Jupiter, FL, U.S.A.), and $2.5 \mu \mathrm{l}$ of $1 \times$ SyBR Green (Molecular Probes, Eugene, Oregon, U.S.A.).

The PCR program consisted of a 4-min incubation at $95^{\circ} \mathrm{C}$ to activate the hot-start recombinant Taq DNA polymerase, followed by 35 cycles of $45 \mathrm{~s}$ at $95^{\circ} \mathrm{C}, 45 \mathrm{~s}$ at $59^{\circ} \mathrm{C}$, and $45 \mathrm{~s}$ at $72^{\circ} \mathrm{C}$, where the fluorescence signal was measured. The specificity of the PCR amplification procedure was checked with a heat dissociation protocol (from 70 to $100^{\circ} \mathrm{C}$ ). The efficiency of the primer set was evaluated by performing real-time PCR on several dilutions of cDNA. The results obtained for the different treatments were normalized to the $18 \mathrm{~S}$ rRNA (AF206926) levels for plants and to the elongation factor (EF1-alfaII) (JF491354) levels for fungi.

Real-time PCR experiments were carried out in separate samples from at least five plants per treatment, with the threshold cycle $\left(\mathrm{C}_{\mathrm{T}}\right)$ determined in triplicate. Relative transcription levels were calculated by using the $2^{-\Delta \Delta \mathrm{Ct}}$ method (Livak and Schmittgen 2001). Negative controls without cDNA were used in all PCR reactions.

\section{Statistical analyses.}

Measures of the percentage of colonization and $\mathrm{M}$ type were subjected to $\chi^{2}$ analyses. Data were subjected to analysis of variance (ANOVA) or two-way ANOVA in a factorial design of two irrigation treatments by two $\mathrm{M}$ colonization treatments in randomized blocks. In order to fulfill the requisites for parametric analyses of the relative levels of transcription data, the two most extreme data of each treatment were eliminated from the data set, and measurements were transformed to the natural logarithm (Rieu and Powers 2009). Statistical analyses were carried out using the SPSS (version 15) statistical package.

\section{ACKNOWLEDGMENTS}

This work was supported by the projects CGL2011-29816 (MINECOFEDER, Spain) and 08812/PI/08 (Fundación Séneca, Región de Murcia Spain). A. Navarro-Ródenas thanks the Ministerio de Educación y Ciencia (MEC) for a Ph.D. grant (FPU Program) and N. Priem for her help on heterologous expression techniques.

\section{LITERATURE CITED}

Alexandersson, E., Fraysse, L., Sjövall-Larsen, S., Gustavsson, S., Fellert, M., Karlsson, M., Johanson, U., and Kjellbom, P. 2005. Whole gene family expression and drought stress regulation of aquaporins. Plant Mol. Biol. 59:469-484.

Aroca, R., Porcel, R., and Ruiz-Lozano, J. M. 2007. How does arbuscular mycorrhizal symbiosis regulate root hydraulic properties and plasma membrane aquaporins in Phaseolus vulgaris under drought, cold or sa- 
linity stresses? New Phytol. 173:808-816.

Aroca, R., Vernieri, P., and Ruiz-Lozano, J. M. 2008. Mycorrhizal and non mycorrhizal Lactuca sativa plants exhibit contrasting responses to exogenous ABA during drought stress and recovery. J. Exp. Bot. 59:20292041.

Aroca, R., Bago, A., Sutka, M., Paz, J. A., Cano, C., Amodeo, G., and Ruiz-Lozano, J. M. 2009. Expression analysis of the first arbuscular mycorrhizal fungi aquaporin described reveals concerted gene expression between salt-stressed and nonstressed mycelium. Mol. Plant-Microbe Interact. 22:1169-1178.

Augé, R. M. 2001. Water relations, drought and vesicular-arbuscular mycorrhizal symbiosis. Mycorrhiza 11:3-42.

Azcon-Bieto, J., and Talón, M. 2008. Fundamentos de Visiología Vegetal. McGraw-Hill Interamericana and Edicions Universitat de Barcelon, Madrid.

Blom, N., Gammeltoft, S., and Brunak, S. 1999. Sequence and structurebased prediction of eukaryotic protein phosphorylation sites. J. Mol. Biol. 294:1351-1362.

Boyd, R., Furbank, R., and Read, D. 1986. Ectomycorrhiza and the water relations of trees. Pages 689-693 in: Physiological and Genetical Aspects of Mycorrhizae. V. Gianinazzi-Pearson and S. Gianinazzi, eds. Kluwer Academic INRAs, Paris.

Calvo-Polanco, M., Zwiazek, J., Jones, M., and MacKinnon, M. 2008. Responses of mycorrhizal jack pine Pinus banksiana seedlings to $\mathrm{NaCl}$ and boron. Trees Struct. Funct. 22:825-834.

Chalot, M., Blaudez, D., and Brun, A. 2006. Ammonia: A candidate for nitrogen transfer at the mycorrhizal interface. Trends Plant Sci. 11:263266.

Chang, S., Puryear, J., and Cairney, J. 1993. A simple and efficient method for isolating RNA from pine trees. Plant Mol. Biol. Rep. 11:113-116.

Chaumont, F., Barrieu, F., Jung, R., and Chrispeels, M. J. 2000. Plasma membrane intrinsic proteins from maize cluster in two sequence subgroups with differential aquaporin activity. Plant Physiol. 122:10251034.

Chaumont, F., Barrieu, F., Wojcik, E., Chrispeels, M. J., and Jung, R. 2001. Aquaporins constitute a large and highly divergent protein family in maize. Plant Physiol. 125:1206-1215.

Coombs, J., Hall, D., Long, S., and Scurlock, J. 1985. Techniques in Bioproductivity and Photosynthesis. Pergamon Press, Elmsford, NY.

Danielson, J., and Johanson, U. 2008. Unexpected complexity of the aquaporin gene family in the moss Physcomitrella patens. BMC Plant Biol. $8: 45$.

Dietz, S., von Bülow, J., Beitz, E., and Nehls, U. 2011. The aquaporin gene family of the ectomycorrhizal fungus Laccaria bicolor: Lessons for symbiotic functions. New Phytol. 190:927-940.

Duddridge, J. A., Malibari, A., and Read, D. J. 1980. Structure and function of mycorrhizal rhizomorphs with special reference to their role in water transport. Nature 287:834-835.

Fetter, K., Van Wilder, V., Moshelion, M., and Chaumont, F. 2004. Interactions between plasma membrane aquaporins modulate their water channel activity. Plant Cell 16:215-228.

Fischer, M., and Kaldenhoff, R. 2008. On the $\mathrm{pH}$ regulation of plant aquaporins. J. Biol. Chem. 283:33889-33892.

Flexas, J., Ribas-Carbó, M., Hanson, D.T., Bota, J., Otto, B., Cifre, J., McDowell, N., Medrano, H., and Kaldenhoff, R. 2006. Tobacco aquaporin NtAQP1 is involved in mesophyll conductance to $\mathrm{CO}_{2}$ in vivo. Plant J. 48:427-439.

Fortas, Z., and Chevalier, G. 1992. Effect of culture conditions on the mycorrhization of Helianthemum guttatum by three species of desert truffles of the genera Terfezia and Tirmania of Algeria.). Can. J. Bot. 70:2453-2460.

Giovannetti, M., Balestrini, R., Volpe, V., Guether M., Straub, D., Costa A., Ludewig U., and Bonfante P. 2012. Two putative-aquaporin genes are differentially expressed during arbuscular mycorrhizal symbiosis in Lotus japonicus. BMC Plant Biol. 12:186.

Gutiérrez, A., Morte, A., and Honrubia, M. 2003. Morphological characterization of the mycorrhiza formed by Helianthemum almeriense Pau with Terfezia claveryi Chatin and Picoa lefebvrei (Pat.) Maire. Mycorrhiza 13:299-307.

Hanba, Y. T., Shibasaka, M., Hayashi, Y., Hayakawa, T., Kasamo, K., Terashima, I., and Katsuhara, M. 2004. Overexpression of the barley aquaporin $\mathrm{HvPIP} 2 ; 1$ increases internal $\mathrm{CO}_{2}$ conductance and $\mathrm{CO}_{2}$ assimilation in the leaves of transgenic rice plants. Plant Cell Physiol. 45:521-529.

Honrubia, M., Morte, A., and Gutiérrez, A. 2007. Las Terfezias. Un cultivo para el desarrollo rural en regiones áridas y semi-áridas. Pages 365-397 in: Truficultura, Fundamentos y Técnicas. S. Reyna, ed. Ediciones Mundi-Prensa, Madrid.

Jahn, T. P., Møller, A. L. B., Zeuthen, T., Holm, L. M., Klærke, D. A., Mohsin, B., Kühlbrandt, W., and Schjoerring, J. K. 2004. Aquaporin homologues in plants and mammals transport ammonia. FEBS (Fed Eur. Biochem. Soc.) Lett. 574:31-36.

Johanson, U., Karlsson, M., Johansson, I., Gustavsson, S., Sjovall, S., Fraysse, L., Weig, A. R., and Kjellbom, P. 2001. The complete set of genes encoding major intrinsic proteins in Arabidopsis provides a framework for a new nomenclature for major intrinsic proteins in plants. Plant Physiol. 126:1358-1369.

Johansson, I., Karlsson, M., Shukla, V. K., Chrispeels, M. J., Larsson, C., and Kjellbom, P. 1998. Water transport activity of the plasma membrane aquaporin PM28A is regulated by phosphorylation. Plant Cell 10:451-460.

Kagan-Zur, V., Raveh, E., Lischinsky, S., and Roth-Bejerano, N. 1994. Initial association between Helianthemum and Terfezia is enhanced by low iron in the growth medium. New Phytol. 127:567-570.

Kammerloher, W., Fischer, U., Piechottka, G. P., and Schäffner, A. R. 1994. Water channels in the plant plasma membrane cloned by immunoselection from a mammalian expression system. Plant J. 6:187199.

Kovács, G., Vágvölgyi, C., and Oberwinkler, F. 2003. In vitro interaction of the truffle Terfezia terfezioides with Robinia pseudoacacia and Helianthemum ovatum. Folia Microbiol. 48:369-378.

Krajinski, F., Biela, A., Schubert, D., Gianinazzi-Pearson, V., Kaldenhoff, R., and Franken, P. 2000. Arbuscular mycorrhiza development regulates the mRNA abundance of Mtaqp; 1 encoding a mercury-insensitive aquaporin of Medicago truncatula. Planta 211:85-90.

Lee, S. H., Calvo-Polanco, M., Chung, G. C., and Zwiazek, J. J. 2010. Role of aquaporins in root water transport of ectomycorrhizal jack pine (Pinus banksiana) seedlings exposed to $\mathrm{NaCl}$ and fluoride. Plant Cell Environ. 33:769-780

Lehto, T., and Zwiazek, J. 2011. Ectomycorrhizas and water relations of trees: A review. Mycorrhiza 21:71-90.

Livak, K. J., and Schmittgen, T. D. 2001. Analysis of relative gene expression data using real-time quantitative PCR and the 2-[Delta][Delta]Ct method. Methods 25:402-408.

Lovisolo, C., Secchi, F., Nardini, A., Salleo, S., Buffa, R., and Schubert, A. 2007. Expression of PIP1 and PIP2 aquaporins is enhanced in olive dwarf genotypes and is related to root and leaf hydraulic conductance. Physiol. Plant. 130:543-551.

Luu, D.-T., and Maurel, C. 2005. Aquaporins in a challenging environment: Molecular gears for adjusting plant water status. Plant Cell Environ. 28:85-96.

Marjanović, Ž., and Nehls, U. 2008. Ectomycorrhiza and water transport. Pages 149-160 in: Mycorrhiza. A. Varma, ed. Springer, Berlin Heidelberg.

Marjanović, Ž., Uehlein, N., Kaldenhoff, R., Zwiazek, J. J., Weia, M., Hampp, R., and Nehls, U. 2005a. Aquaporins in poplar: What a difference a symbiont makes! Planta 222:258-268.

Marjanović, Ž., Uwe, N., and Hampp, R. 2005b. Mycorrhiza formation enhances adaptive response of hybrid poplar to drought. Ann. N. Y. Acad. Sci. 1048:496-499.

Marulanda, A., Azcón, R., and Ruiz-Lozano, J. M. 2003. Contribution of six arbuscular mycorrhizal fungal isolates to water uptake by Lactuca sativa plants under drought stress. Physiol. Plant. 119:526-533.

Maurel, C., Verdoucq, L., Luu, D.-T., and Santoni V 2008. Plant aquaporins: Membrane channels with multiple integrated functions. Annu. Rev. Plant Biol. 59:595-624.

Mexal, J., and Reid, C. P. P. 1973. The growth of selected mycorrhizal fungi in response to induced water stress. Can. J. Bot. 51:1579-1588.

Morte, A., Lovisolo, C., and Schubert, A. 2000. Effect of drought stress on growth and water relations of the mycorrhizal association Helianthe mum almeriense-Terfezia claveryi. Mycorrhiza 10:115-119.

Morte, A., Honrubia, M., and Gutiérrez, A. 2008. Biotechnology and cultivation of desert truffles. Pages 467-483 in: Mycorrhiza, State of the Art, Genetics and Molecular Biology, Eco-Funtion, Biotechnology, EcoPhysiology, Structure and Systematic. A. Varma, ed. Springer, Berlin Heidelberg.

Morte, A., Zamora, M., Gutiérrez, A., and Honrubia, M. 2009. Desert truffle cultivation in semiarid Mediterranean areas. Pages 1-13 in: Mycorrhizas-Functional Processes and Ecological Impact. C. Azcón-Aguilar, J. M. Barea, S. Gianinazzi, and V. Gianinazzi-Pearson, eds. Springer, Berlin Heidelberg.

Morte, A., Navarro-Ródenas, A., and Nicolás, E. 2010. Physiological parameters of desert truffle mycorrhizal Helianthemum almeriense plants cultivated in orchards under water deficit conditions. Symbiosis 52:133-139.

Muhsin, T. M., and Zwiazek, J. J. 2002. Ectomycorrhizas increase apoplastic water transport and root hydraulic conductivity in Ulmus americana seedlings. New Phytol. 153:153-158.

Murashige, T., and Skoog, F. 1962. A revised medium for rapid growth and bio assays with tobacco tissue cultures. Physiol. Plant. 15:473-497. 
Nakamoto, R. K., Rao, R., and Slayman, C. W. 1991. Expression of the yeast plasma membrane $[\mathrm{H}+]$ ATPase in secretory vesicles. A new strategy for directed mutagenesis. J. Biol. Chem. 266:7940-7949.

Navarro-Ródenas, A., Lozano-Carrillo, M., Pérez-Gilabert, M., and Morte, A. 2011. Effect of water stress on in vitro mycelium cultures of two mycorrhizal desert truffles. Mycorrhiza 10:115-119.

Navarro-Ródenas, A., Pérez-Gilabert, M. Torrente, P., and Morte, A. 2012a. The role of phosphorus in the ectendomycorrhiza continuum of desert truffle mycorrhizal plants. Mycorrhiza 22:565-575.

Navarro-Ródenas, A., Ruíz-Lozano, J. M., Kaldenhoff, R., and Morte, A. $2012 \mathrm{~b}$. The aquaporin TcAQP1 of the desert truffle Terfezia claveryi is a membrane pore for water and $\mathrm{CO}_{2}$ transport. Mol. Plant-Microbe Interact. 25:259-266.

Nehls, U., Göhringer, F., Wittulsky, S., and Dietz, S. 2010. Fungal carbohydrate support in the ectomycorrhizal symbiosis: A review. Plant Biol. 12:292-301.

Otto, B., Uehlein, N., Sdorra, S., Fischer, M., Ayaz, M., BelasteguiMacadam, X., Heckwolf, M., Lachnit, M., Pede, N., Priem, N., Reinhard, A., Siegfart, S., Urban, M., and Kaldenhoff, R. 2010. Aquaporin tetramer composition modifies the function of tobacco aquaporins. J. Biol. Chem. 285:31253-31260.

Ouziad, F., Wilde, P., Schmelzer, E., Hildebrandt, U., and Bothe, H. 2006. Analysis of expression of aquaporins and $\mathrm{Na}+\mathrm{H}+$ transporters in tomato colonized by arbuscular mycorrhizal fungi and affected by salt stress. Environ. Exp. Bot. 57:177-186.

Park, W., Scheffler, B., Bauer, P., and Campbell, B. T. 2010. Identification of the family of aquaporin genes and their expression in upland cotton (Gossypium hirsutum L.). BMC Plant Biol. 10:142.

Porcel, R., Azcón, R., and Ruiz-Lozano, J. M. 2004. Evaluation of the role of genes encoding for Delta(1)-pyrroline-5-carboxylate synthetase (P5CS) during drought stress in arbuscular mycorrhizal Glycine max and Lactuca sativa plants. Physiol. Mol. Plant Pathol. 65:211-221.

Porcel, R., Aroca, R., Azcón, R., and Ruiz-Lozano, J. 2006. PIP aquaporin gene expression in arbuscular mycorrhizal Glycine max and Lactuca sativa plants in relation to drought stress tolerance. Plant Mol. Biol. 60:389-404.

Rieu, I., and Powers, S. J. 2009. Real-time quantitative RT-PCR: Design, calculations, and statistics. Plant Cell 21:1031-1033.

Roth-Bejerano, N., Livne, D., and Kagan-Zur, V. 1990. HelianthemumTerfezia relations in different growth media. New Phytol. 114:235238

Roussel, H., Bruns, S., Gianinazzi-Pearson, V., Hahlbrock, K., and Franken, P. 1997. Induction of a membrane intrinsic protein-encoding mRNA in arbuscular mycorrhiza and elicitor-stimulated cell suspension cultures of parsley. Plant Sci. 126:203-210.

Ruiz-Lozano, J. 2003. Arbuscular mycorrhizal symbiosis and alleviation of osmotic stress. New perspectives for molecular studies. Mycorrhiza 13:309-317.

Ruiz-Lozano, J., and Aroca, R. 2008. Last insights into the role of aquaporins in the alleviation of osmotic stress by arbuscular mycorrhizal symbiosis. Pages 139-154 in: Microbial Ecology Research Trends. T. Van Dijk, ed. Nova Science Publisher, Inc., Hauppauge NY, U.S.A.

Ruiz-Lozano, J. M., and Azcón, R. 1995. Hyphal contribution to water uptake in mycorrhizal plants as affected by the fungal species and water status. Physiol. Plant. 95:472-478.

Ruiz-Lozano, J. M., Porcel, R., and Aroca, R. 2006. Does the enhanced tolerance of arbuscular mycorrhizal plants to water deficit involve modulation of drought-induced plant genes? New Phytol. 171:693-698.

Sade, N., Vinocur, B. J., Diber, A., Shatil, A., Ronen, G., Nissan, H., Wallach, R., Karchi, H., and Moshelion, M. 2009. Improving plant stress tolerance and yield production: Is the tonoplast aquaporin SITIP2;2 a key to isohydric to anisohydric conversion? New Phytol. 181:651-661.

Sánchez-Díaz, M., and Aguirreolea, J. 2008a. Transpiración y control estomático. Pages 41-56 in: Fundamentos de Fisiología Vegetal. J. Azcon-Bieto and M. Talón, eds. McGraw-Hill Interamericana and Edicions Universitat de Barcelona, Madrid.

Sánchez-Díaz, M., and Aguirreolea, J. 2008b. El agua en la planta. Movimiento del agua en el sistema suelo-planta-atmósfera. Pages 25-40 in: Fundamentos de Fisiología Vegetal. J. Azcon-Bieto, M. Talón, ed. McGraw-Hill Interamericana and Edicions Universitat de Barcelona, Madrid.

Scholander, P. F., Bradstreet, E. D., Hemmingsen, E. A., and Hammel, H. T. 1965. Sap pressure in vascular plants: Negative hydrostatic pressure can be measured in plants. Science 148:339-346.

Secchi, F., Lovisolo, C., Uehlein, N., Kaldenhoff, R., and Schubert, A. 2007. Isolation and functional characterization of three aquaporins from olive (Olea europaea L.). Planta 225:381-392.

Secchi, F., Maciver, B., Zeidel, M. L., and Zwieniecki, M. A. 2009. Functional analysis of putative genes encoding the PIP2 water channel subfamily in Populus trichocarpa. Tree Physiol. 29:1467-1477.

Steudle, E. 2000. Water uptake by roots: Effects of water deficit. J. Exp. Bot. 51:1531-1542.

Steudle, E., and Peterson, C. A. 1998. How does water get through roots? J. Exp. Bot. 49:775-788.

Temmei, Y., Uchida, S., Hoshino, D., Kanzawa, N., Kuwahara, M., Sasaki, S., and Tsuchiya, T. 2005. Water channel activities of Mimosa pudica plasma membrane intrinsic proteins are regulated by direct interaction and phosphorylation. FEBS (Fed. Eur. Biochem. Soc.) Lett. 579:44174422

Terashima, I., and Ono, K. 2002. Effects of $\mathrm{HgCl}_{2}$ on $\mathrm{CO}_{2}$ dependence of leaf photosynthesis: Evidence indicating involvement of aquaporins in $\mathrm{CO}_{2}$ diffusion across the plasma membrane. Plant Cell Physiol. 43:7078 .

Terashima, I., Hanba, Y. T., Tazoe, Y., Vyas, P., and Yano, S. 2006. Irradiance and phenotype: Comparative eco-development of sun and shade leaves in relation to photosynthetic $\mathrm{CO}_{2}$ diffusion. J. Exp. Bot. 57:343354.

Theodorou, C. 1978. Soil moisture and the mycorrhizal association of Pinus radiata D. Don. Soil Biol. Biochem. 10:33-37.

Theodorou, C., and Bowen, G. D. 1970. Mycorrhizal responses of radiata pine in experiments with different fungi. Aust. For. 34:183-191.

Tinker, P. B., Durall, D. M., and Jones, M. D. 1994. Carbon use efficiency in mycorrhizas theory and sample calculations. New Phytol. 128:115122.

Törnroth-Horsefield, S., Wang, Y., Hedfalk, K., Johanson, U., Karlsson, M., Tajkhorshid, E., Neutze, R., and Kjellbom, P. 2006. Structural mechanism of plant aquaporin gating. Nature 439:688-694.

Turgeman, T., Ben Asher, J., Roth-Bejerano, N., Kagan-Zur, V., Kapulnik, Y., and Sitrit, Y. 2011. Mycorrhizal association between the desert truffle Terfezia boudieri and Helianthemum sessiliflorum alters plant physiology and fitness to arid conditions. Mycorrhiza 21:623-630.

Uehlein, N., Lovisolo, C., Siefritz, F., and Kaldenhoff, R. 2003. The tobacco aquaporin NtAQP1 is a membrane $\mathrm{CO}_{2}$ pore with physiological functions. Nature 425:734-737.

Uehlein, N., Fileschi, K., Eckert, M., Bienert, G. P., Bertl, A., and Kaldenhoff, R. 2007. Arbuscular mycorrhizal symbiosis and plant aquaporin expression. Phytochemistry 68:122-129.

Uehlein, N., Otto, B., Hanson, D. T., Fischer, M., McDowell, N., and Kaldenhoff, R. 2008. Function of Nicotiana tabacum aquaporins as chloroplast gas pores challenges the concept of membrane $\mathrm{CO}_{2}$ permeability. Plant Cell 20:648-657.

Wellburn, A. 1994. The spectral determination of chlorophylls a and b, as well as total carotenoids, using various solvents with spectrophotometers of different resolution. Plant Physiol. 144:307-313.

Wright, D. P., Scholes, J. D., Read, D. J., and Rolfe, S. A. 2000. Changes in carbon allocation and expression of carbon transporter genes in Betula pendula Roth. colonized by the ectomycorrhizal fungus Paxillus involutus (Batsch) Fr. Plant Cell Environ. 23:39-49.

Zardoya, R. 2005. Phylogeny and evolution of the major intrinsic protein family. Biology of the Cell 97:397-414.

Zaretsky, M., Kagan-Zur, V., Mills, D., and Roth-Bejerano, N. 2006. Analysis of mycorrhizal associations formed by Cistus incanus transformed root clones with Terfezia boudieri isolates. Plant Cell Reports 25:62-70.

Zelazny, E., Borst, J. W., Muylaert, M., Batoko, H., Hemminga, M. A., and Chaumont, F. 2007. FRET imaging in living maize cells reveals that plasma membrane aquaporins interact to regulate their subcellular localization. Proc. Natl. Acad. Sci. U.S.A. 104:12359-12364.

\section{AUTHOR-RECOMMENDED INTERNET RESOURCES}

ClustalW: www.ebi.ac.uk/Tools/msa/clustalw2

Compute $\mathrm{pI} / \mathrm{Mw}$ tool: www.expasy.org

MEGA4: www.megasoftware.net/mega.html

National Center for Biotechnology Information: www.ncbi.nlm.nih.gov

Primer 3: frodo.wi.mit.edu

THMM: www.cbs.dtu.dk 